\title{
Effects of Salt Compensation on the Climate Model Response in Simulations of Large Changes of the Atlantic Meridional Overturning Circulation*
}

\author{
THOMAS F. STOCKER \\ Climate and Environmental Physics, Physics Institute, University of Bern, Bern, Switzerland, and International Pacific Research \\ Center, School of Ocean and Earth Science and Technology, University of Hawaii at Manoa, Honolulu, Hawaii \\ Axel Timmermann \\ International Pacific Research Center, School of Ocean and Earth Science and Technology, University of Hawaii at Manoa, \\ Honolulu, Hawaii \\ MANUEl RENOLD \\ Climate and Environmental Physics, Physics Institute, University of Bern, Bern, Switzerland \\ OLIVER TIMM \\ International Pacific Research Center, School of Ocean and Earth Science and Technology, University of Hawaii at Manoa, \\ Honolulu, Hawaii
}

(Manuscript received 31 August 2006, in final form 16 April 2007)

\begin{abstract}
Freshwater hosing experiments with a comprehensive coupled climate model and a coupled model of intermediate complexity are performed with and without global salt compensation in order to investigate the robustness of the bipolar seesaw. In both cases, a strong reduction of the Atlantic meridional overturning circulation is induced, and a warming in the South Atlantic results. When a globally uniform salt flux is applied at the surface in order to keep the global mean salinity constant, this causes additional widespread warming in the Southern Ocean. It is shown that this warming is mainly due to heat transport anomalies that are induced by the specific parameterization in ocean models to represent eddy mixing. Surface salt fluxes tend to move outcropping isopycnals equatorward. As the density perturbation originates at the surface, changes in isopycnal slopes are generated that lead to anomalies in the bolus velocity field. The associated bolus heat flux convergence creates a warming enhancing the bipolar seesaw response, particularly in the Southern Ocean. The importance of this mechanism is illustrated in coupled model simulations in which this parameterization in the ocean model component is switched on or off. Additional experiments in which the same total amount of freshwater is delivered at rates 10 times smaller show that the effect of the global salt compensation is not important in this case, but that the eddy-mixing parameterization is still responsible for a substantial temperature response in the Southern Ocean.
\end{abstract}

\section{Introduction}

The currently most promising hypothesis regarding the characteristic surface temperature pattern associ-

\footnotetext{
* International Pacific Research Center Contribution Number 452.

Corresponding author address: Thomas Stocker, Climate and Environmental Physics, Physics Institute, University of Bern, Sidlerstrasse 5, Bern CH-3012, Switzerland.

E-mail: stocker@climate.unibe.ch
}

DOI: $10.1175 / 2007 J C L I 1662.1$

(C) 2007 American Meteorological Society ated with abrupt climate change is the "bipolar seesaw" (Broecker 1998; Stocker 1998; Clark et al. 2002b; EPICA Community Members 2006), which is based on the observation that the meridional overturning circulation (MOC) causes a substantial south-to-north heat transport in the Atlantic Ocean (Bryden and Imawaki 2001). This transfer of heat from the Southern to the Northern Hemisphere in the Atlantic Ocean cools the South Atlantic if the MOC is active (Crowley 1992; Stocker et al. 1992b). This is readily seen in experiments using climate and ocean models of various complexities in which the MOC is shut off by changing the 
surface buoyancy balance (e.g., see Stouffer et al. 2006 for a recent summary). A shutoff of the Atlantic MOC affects the climate system on a global scale both in the atmosphere and in the ocean. There are also important implications in the Tropics (e.g., a reduction in the Atlantic MOC causes the intertropical convergence zone to move southward into the warmer hemisphere; Timmermann et al. 2005b; Zhang and Delworth 2005). The strongest changes are consistently simulated in the North Atlantic. However, the far-field response is uncertain and varies from model to model. Two comprehensive coupled climate models actually simulated temperature changes in the Southern Ocean that did not even agree in sign (Stocker 2002).

It is the purpose of this paper to investigate the sensitivity of the far-field response to the forcing applied in freshwater experiments. Restoration of the global salt balance is often chosen in such experiments by applying globally uniform corrections. These generally have small effects, but we find that under particular model setups and in the case of large perturbations, their presence may define the sign of the far-field response in certain areas of the Southern Ocean.

The response of the ocean circulation to this correction is linked with the way mixing is parameterized in ocean model components. Subgrid-scale mixing in ocean models is classically represented as lateral diffusion of momentum, heat, and salt. But in order to account for the fact that mixing is most efficient along isopycnal surfaces, the mixing tensor is usually rotated (Redi 1982). Eddy-induced mixing is also shown to be important and is parameterized in ocean models using the Gent-McWilliams (GM) scheme (Gent and McWilliams 1990; Gent et al. 1995). In the GM scheme, eddyinduced mixing is represented as an additional velocity field, the bolus velocity, which is proportional to the slope gradient of the isopycnals. Where isopycnals are steep, this bolus velocity contributes substantially to the general circulation (Danabasoglu et al. 1994) with their strongest effect in the Southern Ocean. Since the restoration of the global salt balance induces surface buoyancy fluxes, which change the position of outcropping isopycnals, an anomalous bolus velocity is expected. Here we quantify the effect of changes in the bolus velocity and show their important role in producing sea surface temperature anomalies.

The paper is organized as follows. In section 2 we present the two coupled models and the experimental setup. Section 3 discusses the ocean model response to various freshwater fluxes. A dynamic feedback producing characteristic far-field responses is presented in section 4 , and the time evolution of different heat source components is given in section 5. Conclusions follow in section 6 .

\section{Model setup and experiments}

The first model we use is the Community Climate System Model, version 3 (CCSM3), developed at the National Center of Atmospheric Research (NCAR) in the low-resolution version (Yeager et al. 2006). This model has a T31 resolution in the atmosphere and a $3^{\circ}$ resolution in the ocean increasing to $0.9^{\circ}$ toward the equator. To best resolve the North Atlantic in such a coarse-resolution version, the pole was put onto Greenland slightly farther south than in the Community Climate System Model, version 2 (CCSM2), thereby improving the resolution of important basins such as the Labrador and Greenland Seas. We use the 25-layer configuration in the ocean; vertical diffusivity is set at $0.4 \times 10^{-4} \mathrm{~m}^{2} \mathrm{~s}^{-1}$. The model produces a stable MOC in the Atlantic at about $16 \mathrm{~Sv}\left(1 \mathrm{~Sv} \equiv 10^{6} \mathrm{~m}^{3} \mathrm{~s}^{-1}\right)$, which unlike in the low-resolution version of CCSM2 is stable and consistent with observational estimates (Ganachaud 2003; Talley et al. 2003). The model does not require flux adjustments and provides a good climatology within the realm of the resolution (Yeager et al. 2006). It is therefore an excellent tool for long-term simulations and for ensemble simulations, which are both required in paleoclimate modeling.

The CCSM3 model simulations comprise a control simulation of $180 \mathrm{yr}$ under 1990 conditions, starting from the 800 -yr simulation performed at NCAR (Yeager et al. 2006), and two different freshwater experiments summarized in Table 1. The ocean model employs a free-surface scheme; however, the freshwater flux perturbation is introduced as a virtual salt flux using a mean salinity of 34.7 for conversion. This has the potential to distort large freshwater fluxes (Griffies 2004). The freshwater flux is delivered into the North Atlantic between $50^{\circ}$ and $70^{\circ} \mathrm{N}$ at a maximum value of 2 Sv. The flux increases linearly in time for $100 \mathrm{yr}$ to the maximum and then decreases linearly to $0 \mathrm{~Sv}$ over the following $100 \mathrm{yr}$ (Fig. 1). This corresponds to a maximum of $18 \mathrm{~m}$ of sea level rise, which is of the order of reconstructions of conditions during the last ice age (Lambeck and Chappell 2001; Yokoyama et al. 2001). All simulations are then carried forward in time to investigate the long-term evolution of the MOC and other oceanic and atmospheric variables, which will be discussed elsewhere.

The freshwater delivered to the North Atlantic causes a substantial reduction of the MOC that evolves on the time scale of the forcing. The minimum MOC at 
TABLE 1. Summary of experiments using the low-resolution version of NCAR CCSM3 (prefix "c" in the experiment label), and the intermediate complexity model ECBilt-CLIO (prefix "e"). " $F_{\max }$ " denotes the peak freshwater flux input into the North Atlantic, "comp." indicates a globally uniform salt flux that compensates the freshwater flux into the North Atlantic in order to keep the global mean salinity constant, and "duration" is the length of the integrations. GM indicates whether the eddy-induced tracer transport parameterization is active or not. Simulations without GM parameterization are labeled with suffix "n."

\begin{tabular}{|c|c|c|c|c|c|c|}
\hline Expt & Model & $F_{\max }(\mathrm{Sv})$ & Comp. & Duration (yr) & GM & Notes \\
\hline cCTRL & CCSM 3 & None & - & 180 & On & Control simulation \\
\hline cFC20 & CCSM 3 & 2.0 & Yes & 780 & On & \\
\hline cFN20 & CCSM 3 & 2.0 & No & 1000 & On & \\
\hline eCTRL & ECBilt & None & - & 1000 & On & Control simulation \\
\hline eFC20 & ECBilt & 2.0 & Yes & 500 & On & \\
\hline eFN20 & ECBilt & 2.0 & No & 500 & On & \\
\hline eFC02 & ECBilt & 0.2 & Yes & 2000 & On & \\
\hline eFN02 & ECBilt & 0.2 & No & 2000 & On & \\
\hline eCTRLn & ECBilt & None & - & 1000 & Off & Control simulation \\
\hline eFC20n & ECBilt & 2.0 & Yes & 500 & Off & \\
\hline eFN20n & ECBilt & 2.0 & No & 500 & Off & \\
\hline $\mathrm{eFC} 02 \mathrm{n}$ & ECBilt & 0.2 & Yes & 2000 & Off & \\
\hline eFN02n & ECBilt & 0.2 & No & 2000 & Off & \\
\hline
\end{tabular}

about 4-6 Sv is achieved toward the end of the perturbation (around year 200). In none of the experiments does the MOC collapse completely even under such strong forcing. Furthermore, in both experiments we observe a recovery of the MOC to a strength that is similar to that at the start of the experiments. This recovery evolves on a much longer time scale than the reduction of the freshwater flux. It takes several centuries to achieve the initial strength of the MOC. This time scale appears to be a robust feature of the MOC response in those models in which the MOC recovers, and it is independent of model complexity (Manabe and Stouffer 1994; Stocker and Schmittner 1997). However, some models indicate that if thresholds are crossed, the Atlantic MOC does not recover and stabilizes at a different equilibrium state (Stocker and Schmittner 1997; Manabe and Stouffer 1999; Mikolajewicz et al. 2007).

In experiment $\mathrm{cFC} 20$, the global salt balance was maintained. This was achieved by extracting the same amount of freshwater uniformly from the remaining ocean surface (i.e., adding salt to the surface layer). This procedure is frequently used when one is interested in the effect of the changes of ocean circulation without changing the global salt concentration and hence keeping the sea level almost constant (Stocker and Wright 1991; Vellinga and Wood 2002; Knutti et al. 2004; Saenko et al. 2004). Other simulations have not used global salt compensation (Mikolajewicz and Maier-Reimer 1994; Manabe and Stouffer 1997; Rind et al. 2001a; Timmermann et al. 2005b; Stouffer et al. 2006). To investigate the effect of this globally uniform salt flux, we have repeated the experiment applying the
2-Sv perturbation without global salt compensation (cFN20).

In the following analyses, the perturbed experiments are compared with cCTRL using decadal averages, and focusing on the decade from years 100 to 110 , the time of maximum freshwater delivery to the North Atlantic. Additional simulations with a maximum freshwater flux of 0.5 and $1 \mathrm{~Sv}$ have been performed. They are not discussed here because all results scale reasonably well with the perturbation.

To investigate the direct influence of the GM parameterization on the temperature changes in response to the freshwater flux forcing, we repeated the simulations with a global climate model of intermediate complexity, the ECBilt-CLIO model (version 3). The atmospheric component ECBilt is a global three-layer model with T21 resolution (Opsteegh et al. 1998) based on quasigeostrophic adiabatic dynamics. Ageostrophic and diabatic forcing terms are added to the prognostic vorticity and thermodynamic equations. The radiation code is linearized for the present-day climate state. The atmosphere is coupled to a fully three-dimensional primitive equation ocean model CLIO (Goosse and Fichefet 1999), which includes a dynamic-thermodynamic sea ice model. In CLIO, the North Atlantic and the Arctic are represented on a rotated grid, while elsewhere the classical longitude-latitude grid is used. The horizontal resolution is $3^{\circ} \times 3^{\circ}$, vertically the ocean is resolved by 20 unevenly distributed $z$ levels. The atmosphere and ocean are coupled by the exchange of heat, momentum, and freshwater. The hydrological cycle is closed by a land bucket model for soil moisture and river runoff is included. However, a small freshwater flux correction is 

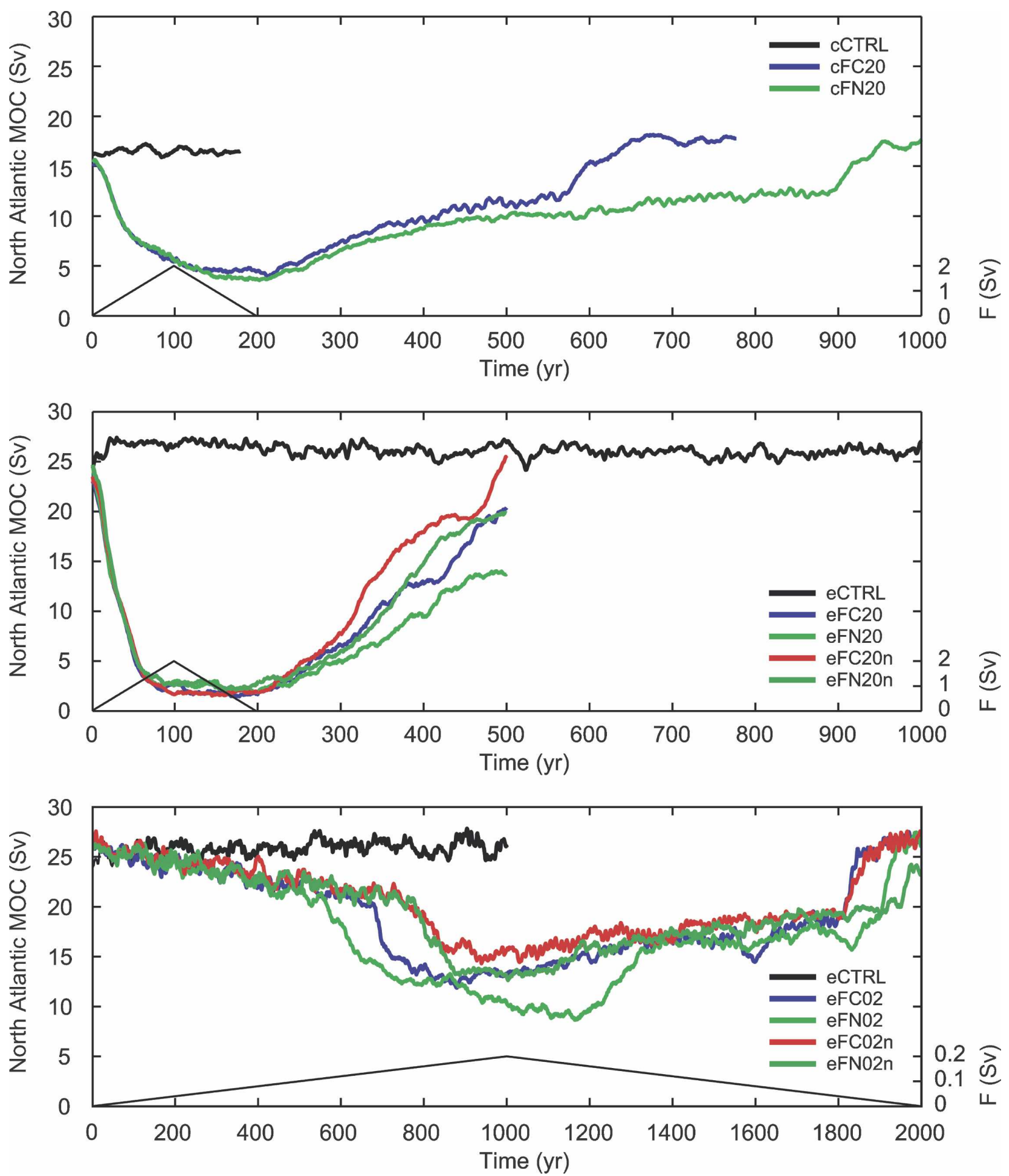

FIG. 1. The MOC in the North Atlantic Ocean for the freshwater experiments using the (top) CCSM3 and (middle), (bottom) ECBilt-CLIO models. Freshwater $F$ is delivered to the North Atlantic and increases linearly during 200 yr with a maximum value of (top), (middle) $2 \mathrm{~Sv}$ or during $2000 \mathrm{yr}$ with a maximum of (bottom) $0.2 \mathrm{~Sv}$. Characteristics of the experiments are given in Table 1 . The MOC is taken as the maximum meridional overturning transport in the Atlantic basin below 500-m depth and north of $28^{\circ} \mathrm{N}$. A 10 -year running mean is applied to smooth the MOC values. 
(a)
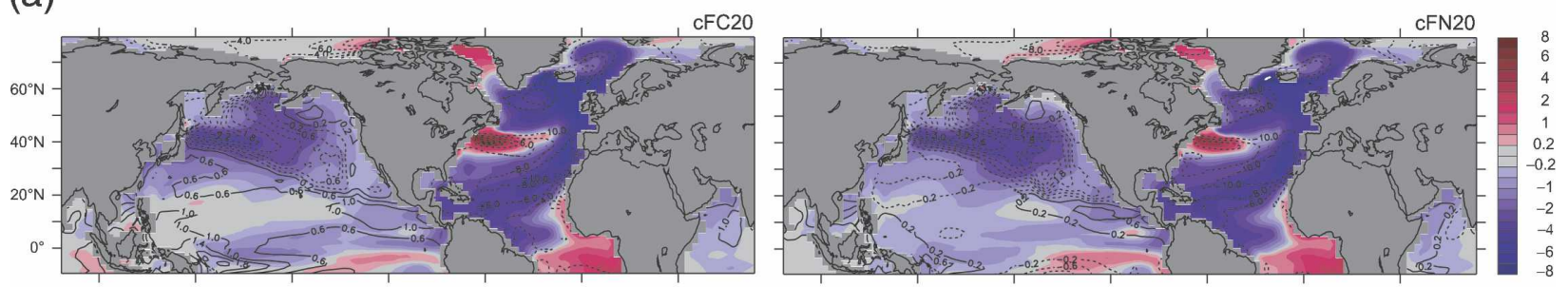

(b)
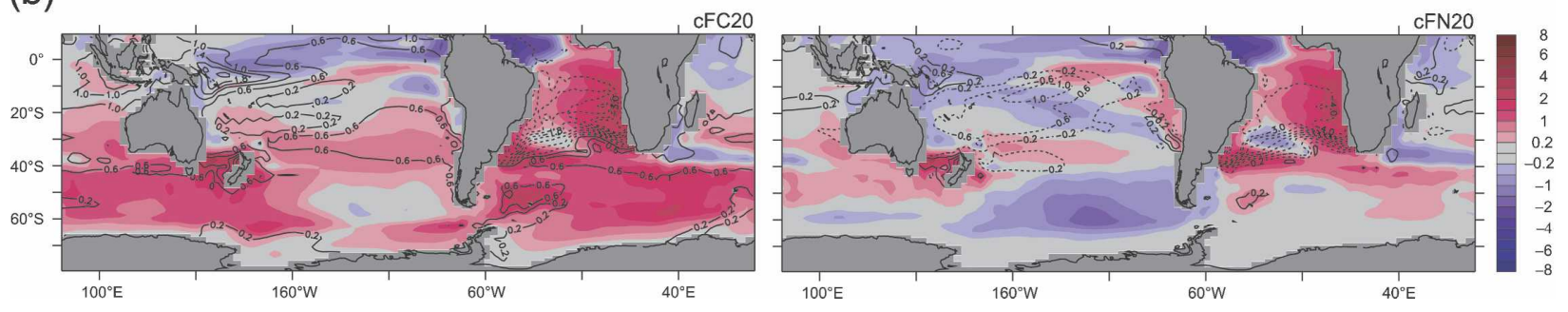

FIG. 2. (a) Changes in SST in K (colors) and sea surface salinity (SSS) in psu (contours) averaged over the top $50 \mathrm{~m}$ and $10 \mathrm{yr}$ starting at year 100 in the Northern Hemisphere for experiments (left) cFC20 and (right) cFN20. The reduction of the MOC produces a cooling of the entire Northern Hemisphere surface ocean except in a localized area at the western boundary between the subtropical and subpolar gyres of the Atlantic Ocean. In cFC20, the subtropical Pacific is becoming more saline due to the flux compensation. Both simulations show a strong freshening of Pacific north of about $30^{\circ} \mathrm{N}$ caused by outflow of freshwater from the Arctic owing to a reversed Bering Strait throughflow during the perturbation. (b) Same as in (a), but for the Southern Hemisphere. The reduction of the MOC produces a warming of the South Atlantic in both experiments. Warming is also strong in the midlatitude Pacific and throughout most of the Southern Ocean in cFC20. Freshwater anomalies arriving from the North Atlantic are arrested at the boundary between the South Atlantic and the Southern Ocean. The effect of the compensating salt flux in experiment cFC20 is evident.

needed in the North Atlantic and North Pacific to obtain a realistic salt distribution with fresher (saltier) North Pacific (Atlantic) waters. Perturbations are applied as real freshwater fluxes (Tartinville et al. 2001).

ECBilt-CLIO simulates a stable and vigorous Atlantic MOC of about $26 \mathrm{~Sv}$ under present-day conditions (Fig. 1). The model has been widely used to study the climate of the past and the role of the MOC during glacial-interglacial climate changes and its stability during warm and cold climate stages (e.g., Goosse et al. 1997; Renssen et al. 2002; Knutti et al. 2004; Renssen et al. 2005; Timmermann et al. 2005a,b; Flückiger et al. 2006; Krebs and Timmermann 2007). Here we take advantage of its low computational cost to produce a total of 10 multicentury integrations (see Table 1). First, we use the standard ocean model that uses the GM parameterization and apply the compensated and uncompensated freshwater flux forcing with peak values of $2 \mathrm{~Sv}$. This enables us to compare results with those of CCSM3 and test the model robustness of the proposed mechanisms (experiments eFC20 and eFN20). Second, we switch off the GM-mixing scheme and repeat the compensated and uncompensated simulations (experiments eFC20n and eFN20n). As in the more complex model CCSM3, the freshwater forcing causes a very similar response of the MOC in ECBilt-CLIO: a fast reduction of the MOC in all four experiments and a slow recovery over several centuries when the forcing has been switched off (Fig. 1).

To assess the importance of the amplitude and duration of the compensating salt flux for the GM effect, we performed the same set of experiments with ECBiltCLIO delivering the same total amount of freshwater but with a maximum amplitude of only $0.2 \mathrm{~Sv}$ delivered to the North Atlantic over 2000 yr (Table 1), rather than $200 \mathrm{yr}$.

\section{Model response at the surface and in meridional basin sections}

Figure 2a compares the sea surface temperature (SST) response of the two simulations cFC20 and cFN20 at the time of maximum freshwater delivery to the Atlantic Ocean (mean from years 100 to 110) in the Northern Hemisphere. Both experiments show the characteristic cooling of the Northern Hemisphere, particularly in the northern North Atlantic. The maximum cooling of the SST is $8.3 \mathrm{~K}$ and occurs south of Iceland due to the cessation of deep-water formation at that location in the model. The model also exhibits a prominent but localized warming around $40^{\circ} \mathrm{N}$ in the North Atlantic, a feature that appears to be characteristic of this low-resolution version of CCSM3 (Bryan et al. 2006), but that is also indicated to a much lesser extent 


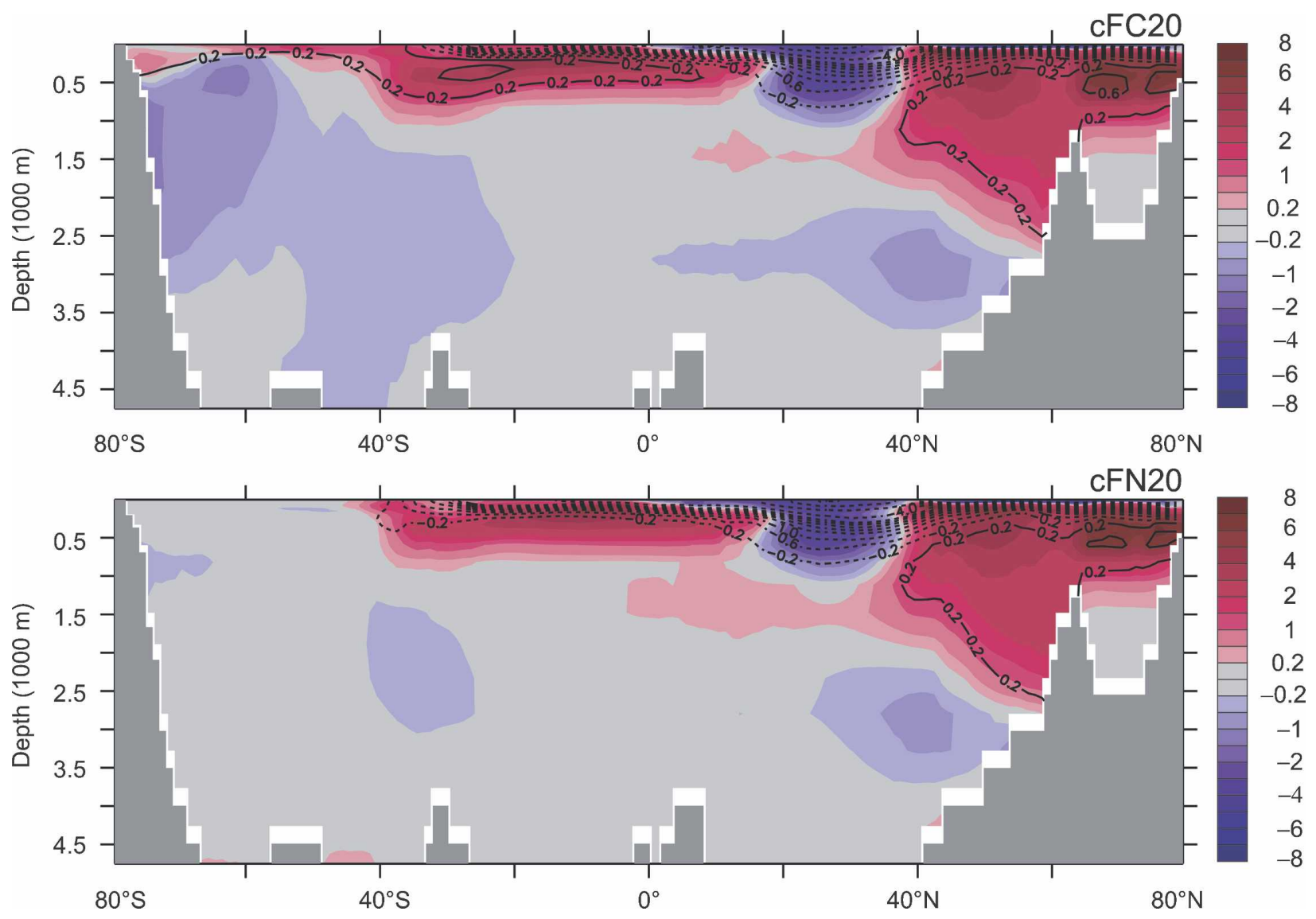

FIG. 3. Changes in temperature in $\mathrm{K}$ (colors) and salinity in psu (SSS, contours) zonally averaged from $70^{\circ} \mathrm{W}$ to $20^{\circ} \mathrm{E}$ covering the Atlantic basin and averaged over 10 yr starting at year 100 for experiments (top) cFC20 and (bottom) cFN20. Below a thin layer of very cold and fresh water, there is widespread warming in the Atlantic due to the cessation of the MOC that injects relatively cold water into the North Atlantic Ocean.

in the averaged response of a number of other models to a freshwater perturbation (Stouffer et al. 2006).

Both experiments exhibit a southward spreading of colder waters along the eastern side of the North Atlantic basin. This is primarily due to the advection of waters from the north (colder) by the subtropical gyre circulation. This flow is also subducted and causes a significant cooling signal in the interior of the North Atlantic Ocean of the upper $1000 \mathrm{~m}$ between $15^{\circ}$ and $35^{\circ} \mathrm{N}$ (see Fig. 3).

The two experiments also share the warming response in the South Atlantic Ocean, which is the essence of the seesaw response associated with changes in the Atlantic MOC (Fig. 2b). This warming is enhanced at the eastern side of the basin due to the combined effect of changes in the gyre circulation and reduced upwelling owing to a decrease of the southeasterly trade winds (Timmermann et al. 2007). Furthermore, in both models equatorward currents diminish as a result of an overall weakening of the overturning circulation.
As shown earlier (Timmermann and Goosse 2004) this leads to a reduction of the supply of cold waters from the South Atlantic and hence an anomalous warming in certain areas of the South Atlantic.

The effect of flux compensation is most evident in the Southern Ocean: cFC20 shows warming throughout this area, whereas for cFN20 this warming is limited to a relatively small region south of Africa and Australia.

Zonal mean meridional sections in the Pacific and Atlantic basins illustrate the vertical structure of temperature and salinity anomalies around year 100 of the freshwater experiments (Fig. 3 for the Atlantic). In the Pacific sector (not shown), temperature changes are generally confined to the upper $1 \mathrm{~km}$ except for a cooling around Antarctica in $\mathrm{cFC} 20$. The subsurface Northern Pacific warms due to the freshening of the surface waters (Fig. 2a). The freshening stabilizes the upper layers and reduces vertical mixing of colder surface waters into the interior. The strong surface freshening is caused by a reversal of the Bering Strait throughflow in 


\section{(a)}
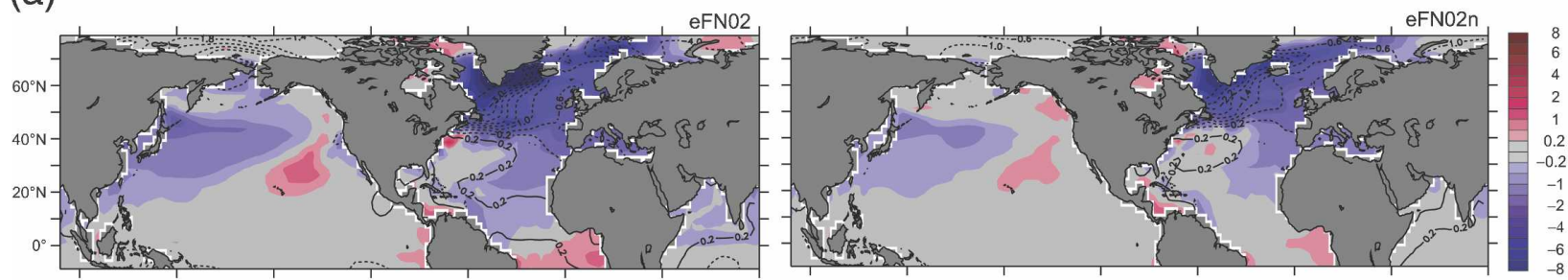

(b)


FIG. 4. (a) Changes in SST in K (colors) and SSS in psu (contours) averaged over the top $50 \mathrm{~m}$ and for 100 yr starting at year 1000 in the Northern Hemisphere for the slow and small freshwater flux (0.2 Sv, $2000 \mathrm{yr})$ without freshwater compensation: (left) eFN02 and (right) eFN02n. The reduction of the MOC produces strong cooling North Atlantic in both experiments. The cooling is somewhat stronger if GM mixing is active. (b) Same as in (a), but for the Southern Hemisphere. The reduction of the MOC produces some warming of the South Atlantic in both experiments. Only if GM mixing is active (top) is warming advected into the Southern Ocean by the mean bolus circulation.

both experiments (Hu et al. 2007). During the freshwater hosing, freshwater flows from the North Atlantic into Arctic. The perturbation in the Atlantic causes a reversal of the Bering Strait transport and enables the fresh surface water to enter the North Pacific where it is picked up by the subpolar gyre. This produces the salinity anomaly pattern apparent in Fig. 2a.

In the Atlantic Ocean, the collapse of the MOC induces a strong cooling that is confined to the uppermost layers (Fig. 3). Underneath, pronounced warming is simulated that is due to the absence of deep-water formation and injection of colder waters from the surface particularly during the winter seasons. However, the cooling between $20^{\circ}$ and $40^{\circ} \mathrm{N}$ can be associated with the subduction of colder surface waters by the subtropical gyre from the east. Differences between $\mathrm{cFC} 20$ and cFN20 are minor for the cross section north of $40^{\circ} \mathrm{S}$.

We investigate whether the basic pattern of northern cooling and southern warming as shown in Fig. 2 also occurs when the same amount of freshwater is delivered to the North Atlantic with a much smaller amplitude but sustained for a longer time. In experiments eFN02 and eFN02n, a triangular freshwater perturbation is applied for $2000 \mathrm{yr}$ with a maximum amplitude of 0.2 Sv. The Atlantic MOC still reduces considerably, but the response is weaker than in the strong hosing experiments (Fig. 1). The Atlantic MOC still reduces notably but the response is weaker than in the strong hosing experiments (Fig. 1). The changes in sea surface temperature are shown at year 1000 of the experi- ment in Fig. 4 for the two cases with (eFN02) and without the GM scheme (eFN02n) but both without global salt compensation. The cooling is strong in both cases and essentially limited to the North Atlantic (Fig. 4a).

In the case of slow freshwater delivery, the salt compensation is not the crucial mechanism to produce the warming in the Southern Ocean due to its very small amplitude (Fig. 4b). Rather the presence of the GM scheme appears to be responsible for the warming that occurs in the Southern Ocean. The GM scheme causes a strong meridional overturning circulation in the Southern Ocean that advects surface waters southward. As the South Atlantic warms upon the reduction of the Atlantic MOC, this warming anomaly is advected southward by the bolus circulation and is then carried eastward by the westerly flow in the Antarctic Circumpolar Current. The warming itself further enhances the additional overturning by thickening the isopycnals, an effect similar to that proposed by Keeling and Visbeck (2005) for a strong freshening of the South Atlantic. When this additional bolus circulation is absent (eFNO2n), no warming is seen in the Southern Ocean (Fig. 4b).

The attention is now focused on changes of water properties in the Southern Ocean. Figure 5 shows a zonal mean from $0^{\circ}$ to $60^{\circ} \mathrm{E}$ of temperature changes and the associated changes of the isopycnals. Experiment $\mathrm{cFC} 20$ and $\mathrm{cFN} 20$ exhibit a different response. The warming in $\mathrm{cFC} 20$ reaches much farther south and 

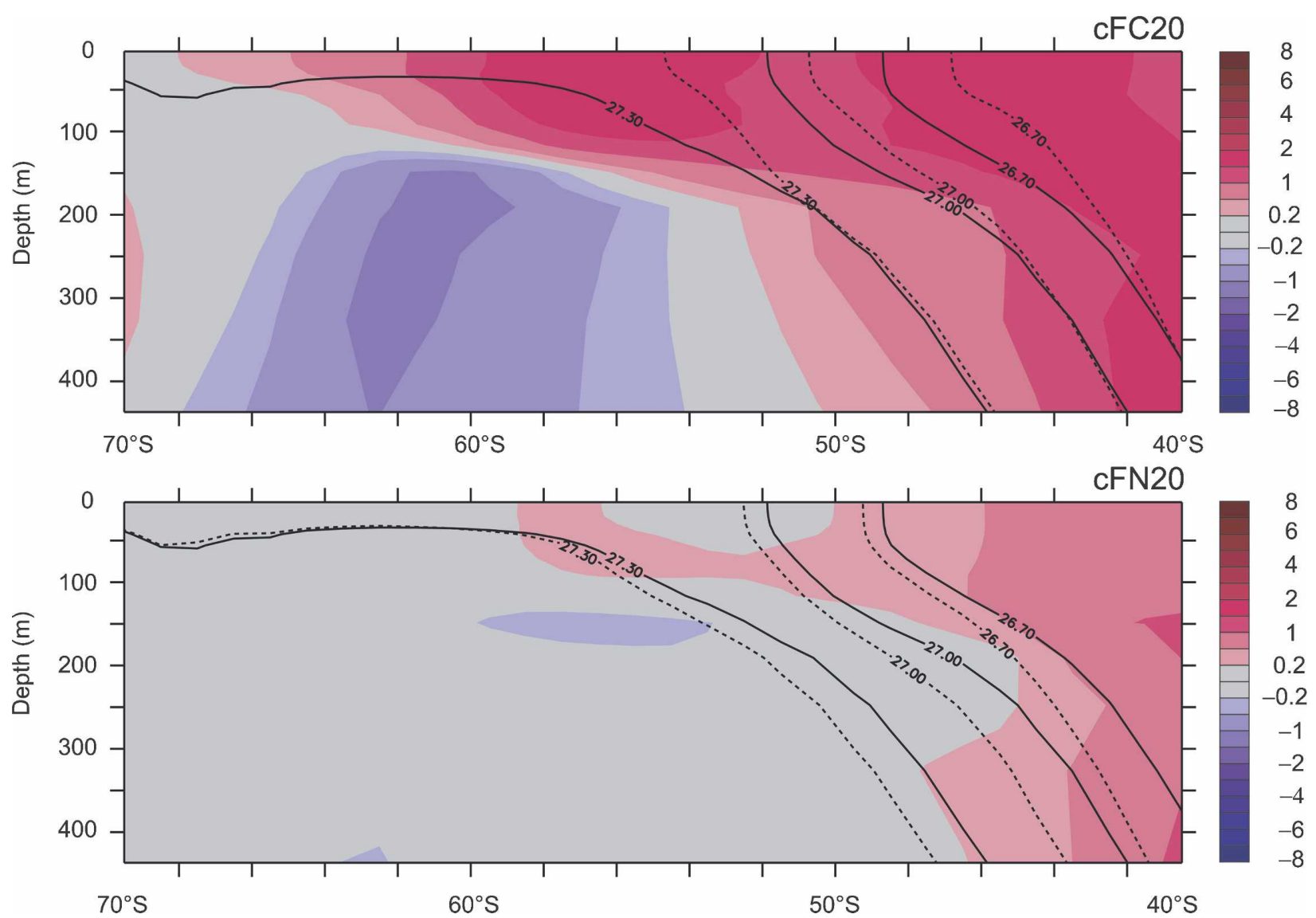

FIG. 5. Zonally averaged changes in temperature in $\mathrm{K}$ (colors) and zonally averaged isopycnals in $\mathrm{kg} \mathrm{m}^{-3}-1000 \mathrm{~kg} \mathrm{~m}^{-3}$ (contours) in the sector from $0^{\circ}$ to $60^{\circ} \mathrm{E}$ coinciding with the area of major warming in the Southern Ocean (see Fig. 2b). Shown are changes between control and means over $10 \mathrm{yr}$ starting at year 100 for experiments (top) cFC20 and (bottom) cFN20. Isopycnals are shown for the control simulation (solid) and the mean over 10 yr starting at year 100 (dashed). In cFC20 the isopycnals move equatorward, whereas for cFN20 they move poleward.

is stronger. This warming would tend to move isopycnals downward and poleward. However, the figure shows that all the isopycnals in $\mathrm{cFC} 20$ have moved equatorward in the freshwater experiment around year 100 compared to the CTRL. The situation is very different in cFN20. Here the isopycnals have moved poleward as expected. The equatorward shift of isopycnals in cFC20 is caused by the compensating surface salt flux that is applied to keep the global salt balance. The change of isopycnal position from the surface affects the slope and hence has a direct effect on the strength of eddy-induced mixing that is parameterized using the GM scheme. This mechanism is presented in the following section.

\section{A dynamic feedback associated with anomalies in bolus velocity}

The warming of large parts of the Southern Ocean seen here in $\mathrm{cFC} 20$ and in other model simulations us- ing salt compensation (Vellinga and Wood 2002; Knutti et al. 2004) cannot be understood solely by the effect of the bipolar seesaw because, as illustrated in Fig. 2b, it is, to a large extent, caused by the application of a uniform salt flux at the surface. There are various ways in which this additional perturbation could affect the temperature near the ocean surface. Additional salt destabilizes the water column and enhances convective activity. If the water that is mixed up toward the surface is warmer, then this would lead to a warming of the near-surface layers. However, in the annual mean, except for locations close to the Antarctic continent, the water column is stably stratified with respect to temperature. Therefore, this effect could only work on a seasonal time scale. During the austral fall, surface waters are cooled below the subsurface temperatures. If vertical mixing sets in, this tends to cool the waters below and warm them near the surface. Such subsurface cooling is not found in the area of interest (not shown).

An efficient mechanism, which is activated in ocean 


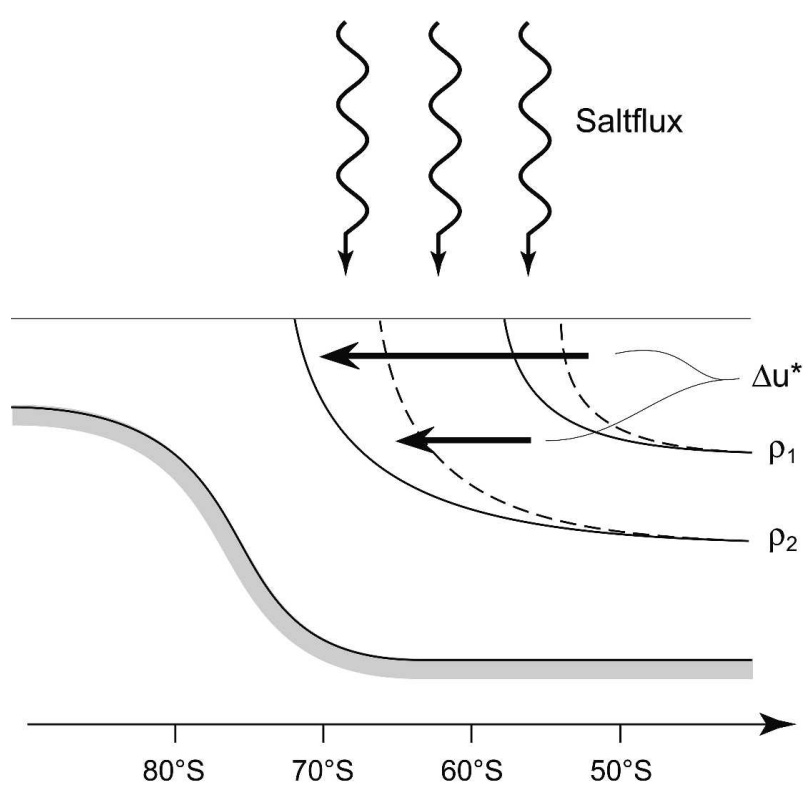

FIG. 6. Schematic illustration of the effect of a surface salt flux on the position of isopycnals. Outcropping isopycnals in the Southern Ocean (solid) move northward to a new position (dashed) when a surface salt flux is applied. As the effect is surface controlled, the response at depth is smaller. This leads to an increase in the steepness of the isopycnals and, using the Gent and McWilliams (1990) parameterization, results in an induced anomalous bolus circulation $\Delta \mathbf{u}^{*}$.

models using the GM scheme for eddy mixing, is associated with the meridional movement of near-surface isopycnals in response to anomalous buoyancy fluxes at the surface. The constant and uniform salt flux makes the surface of the ocean denser and hence moves the outcropping isopycnals equatorward (Figs. 5 and 6). Since this process operates at the sea surface, the changes in isopycnal location at depth are smaller and delayed. As illustrated in Fig. 6, this leads to a general increase of the isopycnal slope. Ocean model components including the GM scheme respond with an anomalous bolus circulation, $\Delta u^{*}$, which tends to restore the original slopes by an associated density advection. The result is enhanced meridional mixing. In areas where strong meridional temperature gradients exist, such enhanced mixing represents an anomalous meridional heat flux. This is particularly the case in the Southern Ocean.

The bolus velocity (Gent et al. 1995) is given by

$$
\begin{aligned}
u^{*} & =\kappa\left(\rho_{x} / \rho_{z}\right)_{z}, \\
v^{*} & =\kappa\left(\rho_{y} / \rho_{z}\right)_{z}, \\
w^{*} & =-\kappa\left[\left(\rho_{x} / \rho_{z}\right)_{x}+\left(\rho_{y} / \rho_{z}\right)_{y}\right],
\end{aligned}
$$

where subscripts denote partial derivatives, and $\kappa$ is an isopycnal thickness diffusivity. In the ocean model com- ponent of CCSM3 $\kappa=800 \mathrm{~m}^{2} \mathrm{~s}^{-1}$, and $\kappa=200 \mathrm{~m}^{2} \mathrm{~s}^{-1}$ in ECBilt-CLIO. If the bolus circulation occurs in an ambient temperature field, associated heat fluxes can be calculated. The convergence of the bolus heat flux, a "bolus heat source," is given by

$$
q^{*}=-\boldsymbol{\nabla} \cdot\left(\mathbf{u}^{*} T\right)=-\mathbf{u}^{*} \cdot \nabla T,
$$

where $\mathbf{u}^{*}$ denotes the bolus velocity vector with $\boldsymbol{\nabla} \cdot \mathbf{u}^{*}$ $=0$ following from (1). We use the operator $\Delta$ to denote anomalies, that is, the difference between a quantity $A$ of an experiment and the time average of that quantity in the respective control run, $\bar{A}$,

$$
\Delta A=A-\bar{A} .
$$

The anomalous bolus heat source can be decomposed into three components:

$$
\begin{aligned}
\Delta q^{*} & =\Delta\left(-\mathbf{u}^{*} \cdot \boldsymbol{\nabla} T\right) \\
& =-\left(\Delta \mathbf{u}^{*}\right) \cdot \bar{\nabla} T-\overline{\mathbf{u}^{*}} \cdot \Delta(\boldsymbol{\nabla} T)-\left(\Delta \mathbf{u}^{*}\right) \cdot \Delta(\boldsymbol{\nabla} T) .
\end{aligned}
$$

The three terms on the rhs of (4) denote the heat source anomalies due to bolus velocity anomalies, temperature gradient anomalies, and correlations thereof, respectively. In the analysis below we report depth averages of (4) from 50- to 150-m depth.

Figure 7 shows the bolus heat source anomaly in the Southern Hemisphere for experiments $\mathrm{cFC} 20$ and cFN20. The spatial extent of $\Delta q^{*}$ corresponds well with that of the temperature anomalies in the Southern Ocean. Consistent with this, experiment cFN20 shows warming only in a small area outside the South Atlantic Ocean indicating that a large fraction of the warming in cFC20 is actually due to this mechanism. Heating rates are on the order of $0.2-0.5 \mathrm{~K} \mathrm{yr}^{-1}$, which is more than sufficient to produce the temperature anomalies of 1-2 $\mathrm{K}$ around year 100. However, the bolus heat source is not the dominant mechanism in all regions to create the temperature anomalies. For example, in the South Atlantic, the warming is caused by changes in the current associated with the reduction of the MOC, as will be shown below.

A decomposition of $\Delta q^{*}$ according to (4) shows that the anomalous bolus velocity provides most of the heating, while changes in the temperature gradient are of minor importance. Correlations between changes in $\mathbf{u}^{*}$ and $\boldsymbol{\nabla} T$ are also unimportant (not shown).

Since bolus velocities are typically much smaller than current velocities in most areas of the ocean, we need to determine the relative importance of heating anomalies caused by anomalies of current velocity and bolus velocity. Changes in Atlantic MOC imply large changes in the current velocity $\mathbf{u}$, and therefore, this raises the possibility of large heating anomalies. We now compare 

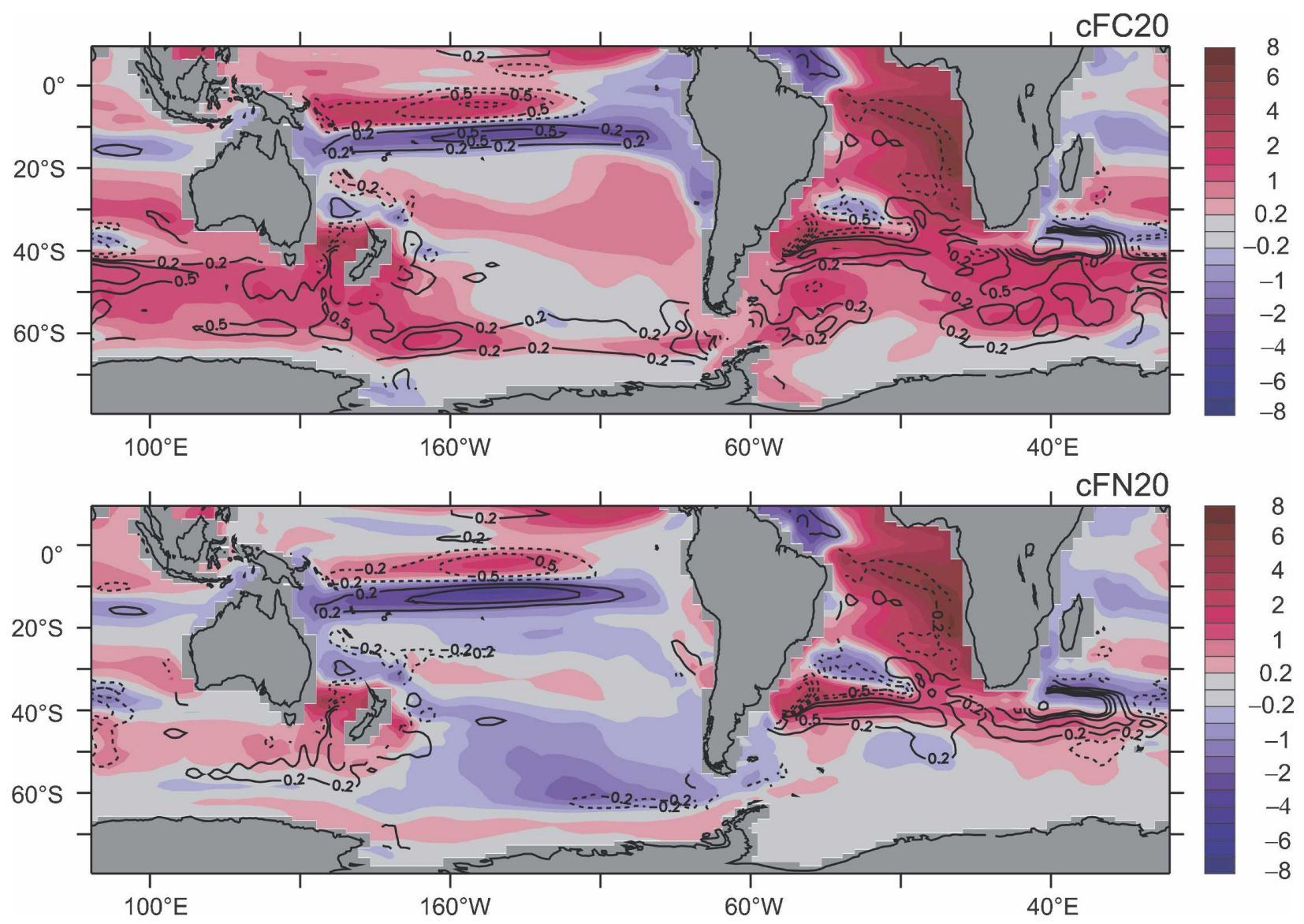

FIG. 7. Depth-averaged temperature anomaly from $50-$ to $150-\mathrm{m}$ depth in $\mathrm{K}$ (color) and bolus heat source anomaly, $\Delta q^{*}$ (contours), averaged over the same depth in $\mathrm{K} \mathrm{yr}^{-1}$ for the Southern Hemisphere: (top) cFC20 and (bottom) cFN20. The extended warming area in cFC20 correlates well with positive anomalies of $\Delta q^{*}$. Contour levels for $\Delta q^{*}$ are $\pm(0.2,0.5,1,1.5,2,4,6, \ldots) \mathrm{K} \mathrm{yr}{ }^{-1}$. Values are calculated from decadal averages from years 100 to 110 , the time of maximum forcing.

the bolus heating rate anomalies $\Delta q^{*}$ with those caused by changes in the current velocity,

$$
q=-\nabla \cdot(\mathbf{u} \cdot T)=-\mathbf{u} \cdot \boldsymbol{\nabla} T,
$$

for the Northern and Southern Hemispheres. Figure 3 indicated strong subsurface warming in the northern North Atlantic the cooling below about $40^{\circ} \mathrm{N}$. Anomalies of $\Delta q$ correlate well with these temperature patterns. A decomposition of (5) analogous to (4) reveals that most of the cooling in the midlatitude Atlantic is due to current changes that suggests that this is caused by a changed strength and northward shift of the subtropical gyre. Incidentally, this is also the reason for the conspicuous warming tongue visible in Fig. 2a. Conversely, the subsurface warming north of $40^{\circ} \mathrm{N}$ is mainly caused by changes in the temperature gradient, which is the result of an efficient inhibition of convective mixing when the surface freshwater flux is applied. In the Northern Hemisphere, $\Delta q^{*}$ is small and has a negligible effect on the temperature structure. Only in a small area in the western North Atlantic where large temperature, and hence density, anomalies are caused by a shift of the subtropical gyre, are $\Delta q *$ identified, but they are still overwhelmed by $\Delta q$.

Using a coupled model of intermediate complexity, we now show the dependence of the bolus heat convergence on the mixing parameterization employed in the ocean model component. The EcBilt-CLIO model is run under present-day conditions with GM mixing on (eCTRL) and off (eCTRLn). Experiments eFC20 and eFC20n are simulations with salt compensation and GM mixing on and off, respectively. Analogously, eFN20 and eFN20n are the corresponding experiments without compensation. With these four additional simulations the effect of the salt compensation can be quantified for the cases of GM mixing on or off. Also, one can determine the effect of the GM scheme for salt compensation on or off. 

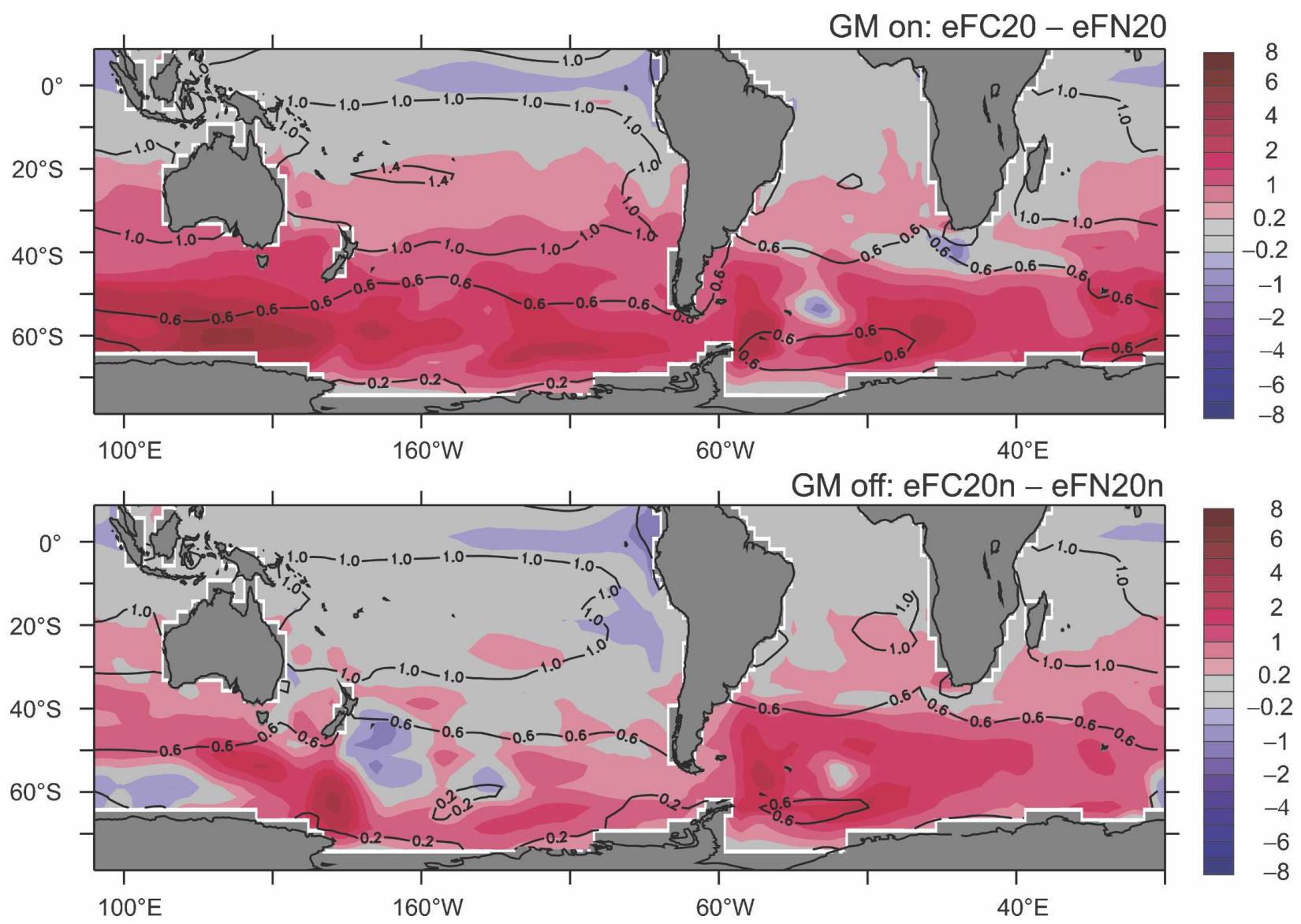

FIG. 8. Temperature differences in $\mathrm{K}$ between a compensated and noncompensated experiment for (top) GM parameterization on (eFC20 - eFN20) and (bottom) for GM parameterization off (eFC20n - eFN20n). Averages are taken over the years 100-150. Contours are salinity differences in psu between eFC20 and eFN20 (eFC20n and eFN20n), which illustrate the effect of salinity compensation. Simulations are done with the EcBilt-CLIO model.

Figure 8 shows the difference of the depth-averaged temperature anomalies around year 100 in the Southern Hemisphere between the compensated and the noncompensated runs. When GM is switched on (Fig. 8 , top) the warming due to the compensation is substantial and widespread. The effect is weaker if GM is off (Fig. 8, bottom), which demonstrates the key role of the GM scheme in enhancing the warming response when compensation is applied. This is consistent with the finding in experiments eFN02 and eFNO2n (Fig. 4) that GM mixing is crucial in spreading the temperature anomaly from the South Atlantic into the Southern Ocean.

Note also in Fig. 8, that the differences in the South Atlantic for both cases are small. This is expected as the cause of the warming there does not depend on the compensation or the presence of the GM mixing but rather on the altered meridional circulation. To isolate the effect of the GM mixing, we calculate the differences $($ eFC20 - eCTRL $)-(e F C 20 n-e C T R L n)$, and
$($ eFN20 - eCTRL $)-($ eFN20n - eCTRLn $)$ as shown in Fig. 9. The GM mixing is responsible for an additional warming in most areas of the Southern Ocean in both the compensated and uncompensated case. However, the warming becomes more intense when salt flux compensation is applied.

These additional experiments using a different coupled model emphasize that the warming caused by anomalous bolus heat convergence is a robust mechanism, at least within the framework of these two rather different models. The spatially uniform salt flux compensation induces surface buoyancy fluxes and an indirect thermal effect that cannot be neglected in ocean models using the GM-mixing scheme.

\section{Evolution of the different heating components during a freshwater experiment}

To quantify the role of the different terms in (4) during the freshwater experiment, we calculate mean 

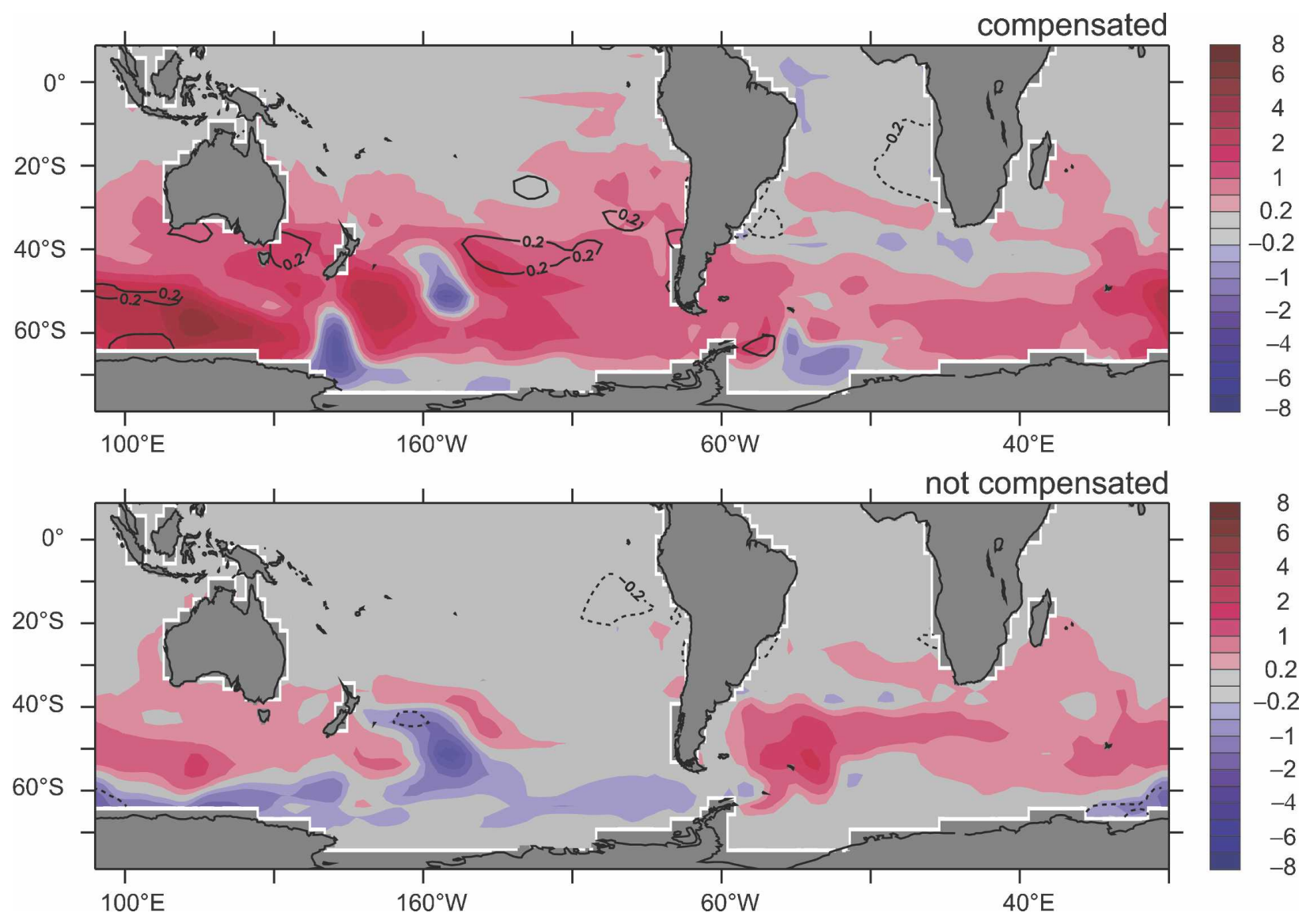

FIG. 9. Temperature differences in $\mathrm{K}$ caused by the GM parameterization for a simulation (top) with freshwater compensation $[(\mathrm{eFC} 20-\mathrm{eCTRL})-(\mathrm{eFC} 20 \mathrm{n}-\mathrm{eCTRLn})]$ and $($ bottom $)$ without salt compensation [(eFN20 - eCTRL) - (eFN20n - eCTRLn)] Averages are taken over the years 100-150. Salinity differences in psu are small because differences are taken between two compensated and two noncompensated experiments, respectively. Simulations are done with the EcBilt-CLIO model. Note that the anomalies include the differences in the CTRL states that are, however, small (not shown).

heating rates in two areas of the Southern Hemisphere based on the CCSM3 experiments (Fig. 10). The first area covers the South Atlantic from $40^{\circ} \mathrm{S}-0^{\circ}$ to $60^{\circ} \mathrm{W}-$ $20^{\circ} \mathrm{E}$ (hereafter region SA), the second spans a large region of the Southern Ocean $\left(40^{\circ}-70^{\circ} \mathrm{S}, 10^{\circ}-160^{\circ} \mathrm{W}\right.$, hereafter region $\mathrm{SO}$ ). In region SA the differences between experiments $\mathrm{cFC} 20$ and $\mathrm{cFN} 20$ are small and not considered significant (i.e., the simulated patterns are robust and independent of the details of the freshwater forcing). Figure 11 compares $\Delta q$ with $\Delta q^{*}$ in the South Atlantic. The warming cannot be explained by changes in bolus velocity as $\Delta q^{*}$ is actually negative. In contrast, the warming is driven by changes in the current, while the other contributions to $\Delta q$ are small or even negative in sign. This is the major mechanism for the thermal bipolar seesaw (Stocker and Johnsen 2003).

In region $\mathrm{SO}$, the situation is opposite. Heating anomalies due to changes in current heat flux are negative throughout, but they are unable to cancel the large heating rates provided by bolus heat flux convergences (Fig. 12). It is evident, that changes in the current velocity are small and $\Delta q$ is mostly a consequence of changes in $\nabla T$. In region SO, the anomalies in bolus velocity are caused by the salt flux applied at the ocean surface, and most of $\Delta q^{*}$ is due to $-\left(\Delta \mathbf{u}^{*}\right) \cdot \bar{\nabla} T$. This is also demonstrated by comparing the time series of the two experiments cFC20 and cFN20 as shown in Fig. 13. For $\mathrm{cFC} 20$ the averaged warming is more than $1.2 \mathrm{~K}$, whereas it is only about $0.3 \mathrm{~K}$ in cFN20. The temporal evolution of the warming closely follows the salt flux forcing, which increases linearly until year 100 and decreases from year 100 to 200 . The heating rates are leading the temperature changes (Fig. 13, top) in cFC20. In cFN20, all components of the bolus heat flux convergence are small and uncorrelated with the warming.

To determine whether heating rates of about $0.3 \mathrm{~K}$ $\mathrm{yr}^{-1}$ are sufficient to produce near-surface temperature 

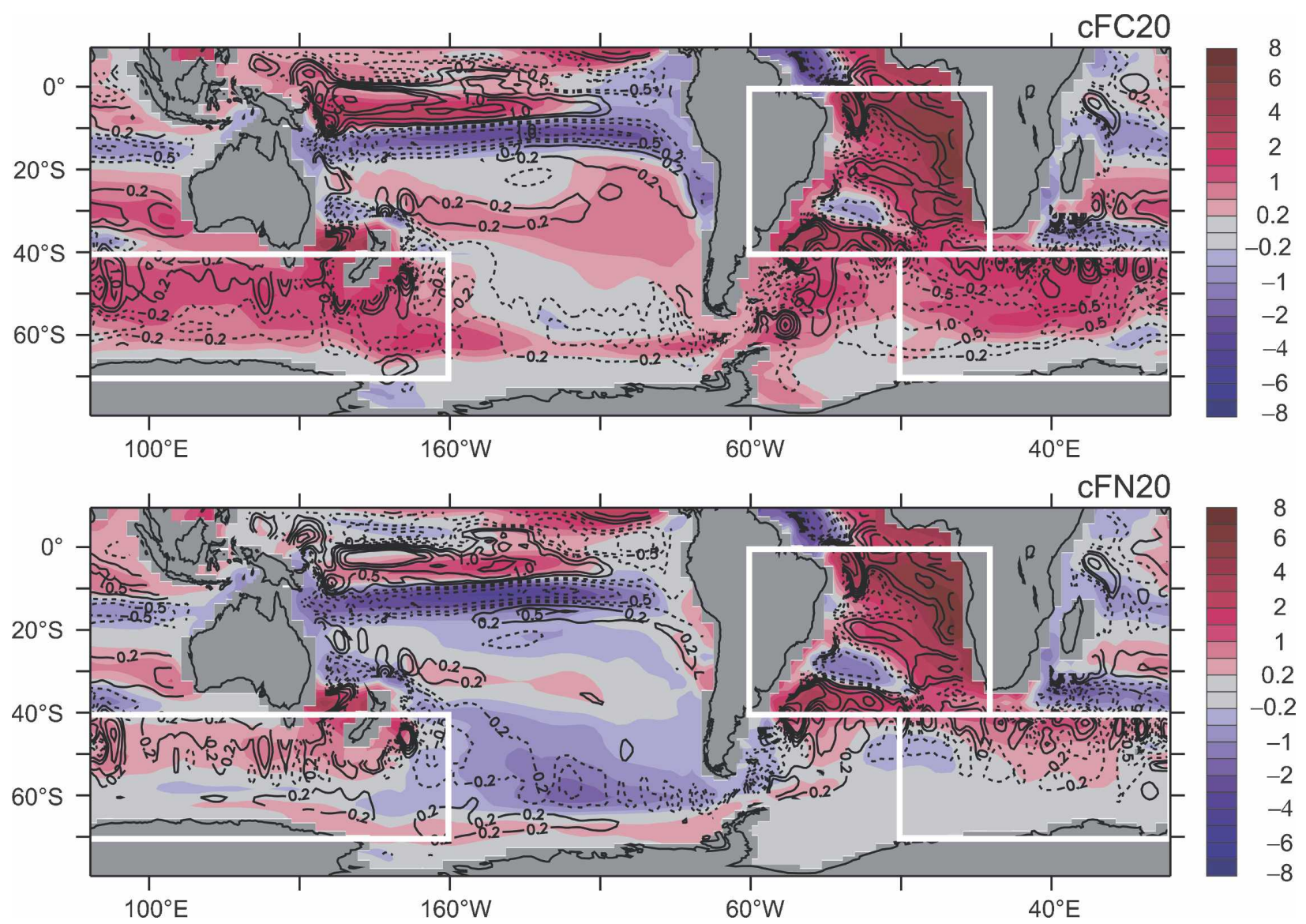

FIG. 10. Same as in Fig. 7, but for the heat source anomaly caused by changes in the current velocity instead of the bolus velocity. Contours are now of $\Delta q$. The two areas in the South Atlantic and the one area in the Southern Ocean in which mean heating rates are calculated, are outlined in white.

anomalies, we have estimated the damping time scale in the depth range of $100-200 \mathrm{~m}$ in the control run cCTRL. From the monthly mean temperature values for the $180 \mathrm{yr}$ of the control simulation a mean seasonal cycle has been subtracted to obtain monthly anomalies. Assuming that each time series $X(t)$ can be approximated by an autoregressive process of order $1, \mathrm{AR}[1]$, $X(t+\Delta t)=\alpha X(t)+\varepsilon(t)$, where $\varepsilon(t)$ represents white noise, one can estimate $\hat{\alpha}=\langle X(t), X(t+\Delta t)\rangle /\langle X(t)$, $X(t)\rangle$ and the corresponding time scale $\tau=\Delta t /(1-\hat{\alpha})$ with $\Delta t=1$ month. In the South Atlantic region $\left(0^{\circ}-\right.$ $40^{\circ} \mathrm{S}$ ) we find $\tau \approx 25$ months, in the Southern Ocean $\left(40^{\circ}-70^{\circ} \mathrm{S}, 10^{\circ}-160^{\circ} \mathrm{W}\right)$ the estimate yields $\tau \approx 20$ months. A heating rate $\Delta q^{*} \approx 0.3 \mathrm{~K} \mathrm{yr}^{-1}$ therefore produces a temperature anomaly $\Delta T \approx \tau \Delta q^{*} \approx 0.5 \mathrm{~K}$, which is of the same order of magnitude as the one simulated.

Changes in $\mathbf{u}^{*}$ can be caused by both anomalies in temperature and salinity through their effects on density. To demonstrate that the changes in salt are primarily responsible for the bolus velocity anomalies, we present the time series of experiment $\mathrm{cFC} 20$ for two cases in which salinity (Fig. 14, top), or temperature (Fig. 14, bottom) of the control run are constant in the diagnostic calculations of Eq. (1). Ignoring changes in salinity, results in small heating rates that are not well correlated with the temperature anomalies. Conversely, keeping temperature constant, substantial heating anomalies are obtained that exceed those from the full calculation of $\Delta q^{*}$ (Fig. 14, top). This demonstrates that it is the changes in salinity that are mainly responsible for the movement of the isopycnals and the induced bolus velocity anomalies.

\section{Discussion and conclusions}

Using two independent coupled climate models of differing complexity freshwater flux experiments were performed to investigate the robustness of the temperature response in the South Atlantic-Southern Ocean area, which results from large changes in the Atlantic MOC. These were induced by delivering linearly in- 

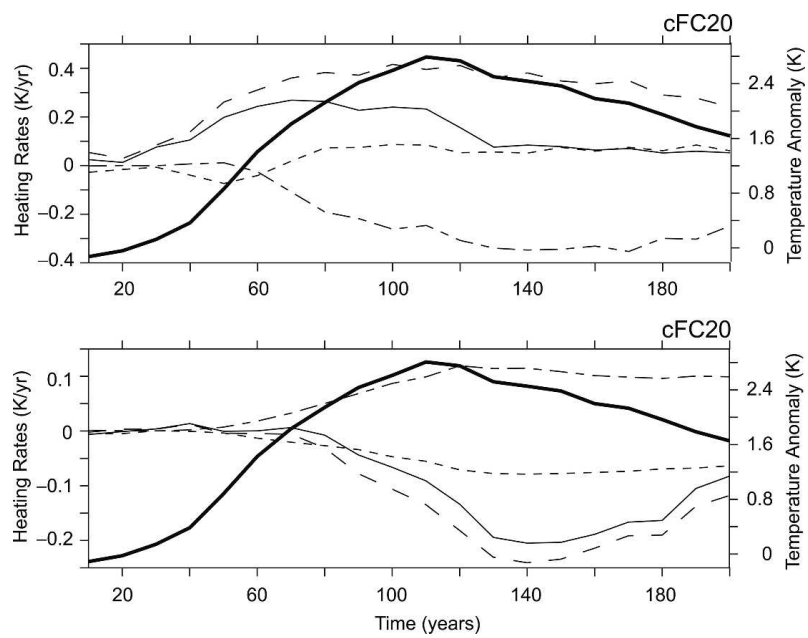

FIG. 11. Time series of the temperature anomaly (bold) and the heating anomaly (top) $\Delta q$ (black fine) and (bottom) $\Delta q^{*}$ (black fine) averaged over the area of the South Atlantic $\left(40^{\circ} \mathrm{S}-0^{\circ}\right.$, $60^{\circ} \mathrm{W}-20^{\circ} \mathrm{E}$ as shown) for expt $\mathrm{cFC} 20$. Lines denote the three heating anomaly components $-(\Delta \mathbf{u}) \cdot \bar{\nabla} T$ (long dashed), $-\overline{\mathbf{u}} \cdot \Delta(\boldsymbol{\nabla} T)$ (short dashed), and $-(\Delta \mathbf{u}) \cdot \Delta(\boldsymbol{\nabla} T)$ (short and long dashed) for $\Delta q$ and $\Delta q^{*}$ according to (4).

creasing freshwater fluxes to the North Atlantic between $50^{\circ}$ and $70^{\circ} \mathrm{N}$. To keep the global mean salinity constant, the same total freshwater flux was extracted uniformly from the remaining ocean area. We showed that in the Southern Ocean, this salt flux moves the position of the outcropping isopycnals equatorward and thus increases the isopycnal slope. This induces an anomalous bolus velocity that tends to restore the position of the isopycnals. Superimposed on strong temperature gradients in the Southern Ocean, this leads to warming in those areas. In an experiment in which no
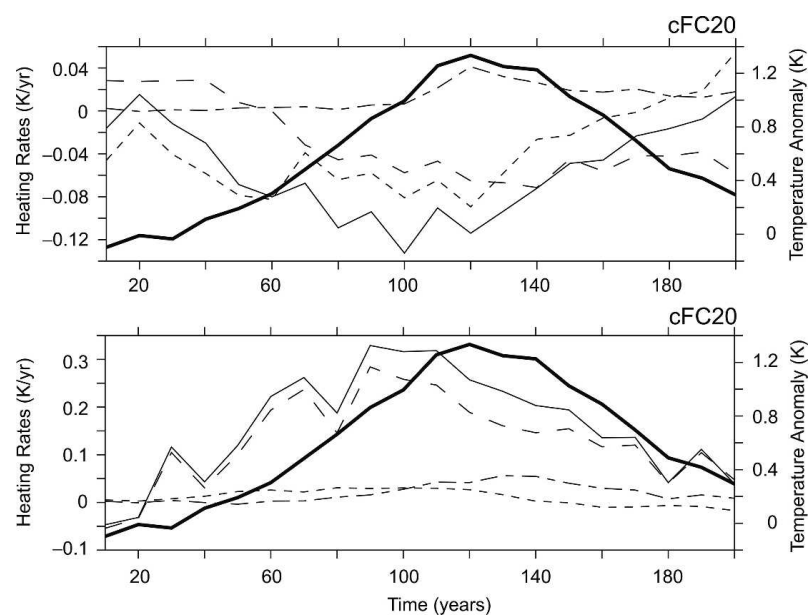

FIG. 12. Same as in Fig. 11, but for the area of the Southern Ocean $\left(70^{\circ}-40^{\circ} \mathrm{S}, 10^{\circ}-160^{\circ} \mathrm{W}\right)$.
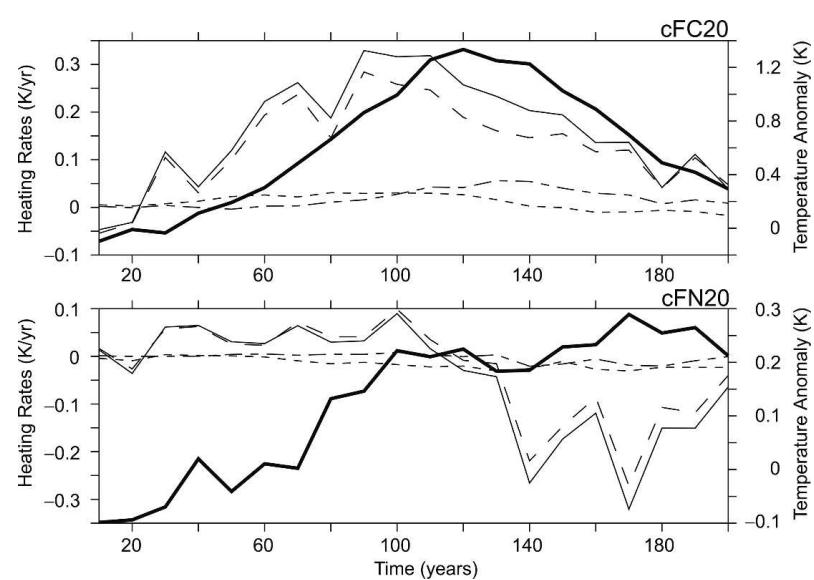

FIG. 13. Time series of the temperature anomaly (bold) and the heating anomaly $\Delta q^{*}$ (black fine) averaged over the area of the Southern Ocean $\left(70^{\circ}-40^{\circ} \mathrm{S}, 10^{\circ}-160^{\circ} \mathrm{W}\right)$ for expt (top) $\mathrm{cFC} 20$ and (bottom) cFN20. Lines denote the three heating anomaly components $-\left(\Delta \mathbf{u}^{*}\right) \cdot \bar{\nabla} T$ (long dashed), $-\overline{\mathbf{u}}^{*} \cdot \Delta(\boldsymbol{\nabla} T)$ (short dashed), and $-\left(\Delta \mathbf{u}^{*}\right) \cdot \Delta(\nabla T)$ (short and long dashed) according to (4).

such compensation is applied, the warming in the Southern Ocean is smaller in extent and the bolus heating anomalies are very small or even negative in sign. Therefore, a substantial part of the warming in the Southern Ocean is due to the locally applied salt flux intended to balance the global mean salinity.

We have shown that this mechanism is present in two very different coupled models both of which include

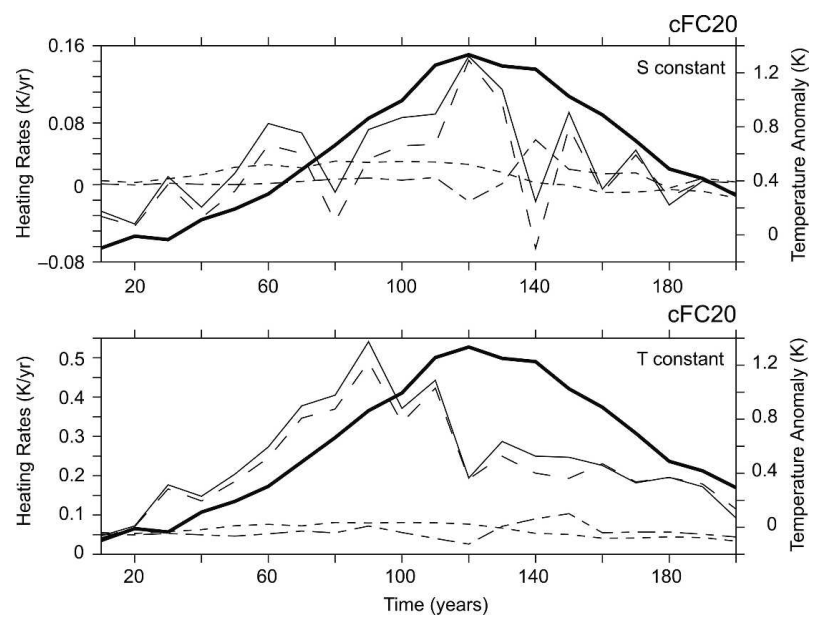

FIG. 14. Time series of the temperature anomaly (bold) and the heating anomaly $\Delta q^{*}$ (black fine) averaged over the area of the Southern Ocean $\left(70^{\circ}-40^{\circ} \mathrm{S}, 10^{\circ}-160^{\circ} \mathrm{W}\right)$ for expt cFC20. The influence of changes in salinity or temperature on the bolus velocity $\mathbf{u}^{*}$ and hence $\Delta q^{*}$ are determined by keeping (top) salinity or (bottom) temperature at the values of the control run when evaluating $\mathbf{u}^{*}$. Lines denote the three heating anomaly components as in Fig. 13. 
comprehensive ocean components. This suggests that the mechanism may be a robust feature that is not dependent on the exact formulation of the coupled model.

Consistent with our mechanism, the warming signal in the Southern Ocean is substantially reduced if the GM-mixing scheme is not utilized. Indeed, GM mixing is not employed in the models of Manabe and Stouffer (2000), and these transient simulations only show warming in the South Atlantic. Temperature differences between two different modes (MOC on and MOC off), however, exhibit widespread warming in the Southern Hemisphere (e.g., Manabe and Stouffer 1999) indicating that the long-term evolution is not dependent on the response of the GM mixing to the compensation. This is consistent with our additional experiments (eFC02, eFN02, etc.) where we found that the weak compensation in the $0.2-\mathrm{Sv}$ freshwater experiments did not alter the response in the Southern Ocean. However, the presence of GM mixing in this model enhanced warming of the Southern Ocean substantially due to the southward advection of temperature anomalies of the South Atlantic by the mean bolus circulation.

Our results have implications for the interpretation of freshwater hosing simulations using global climate models. It was noted that the response of these models is robust in the Northern Hemisphere, but outside the Atlantic Ocean basin, temperature changes exhibit inconsistent signs between different models (Stocker 2002). Although the two experimental setups cannot be compared quantitatively, it is evident that the Hadley model produces a widespread warming in the Southern Hemisphere (Vellinga and Wood 2002), while the Goddard Institute for Space Studies (GISS) model shows cooling around Antarctica (Rind et al. 2001b). Freshwater was compensated in the Hadley model experiments suggesting that the process described here may have contributed, if not determined, the warming in the Southern Hemisphere. On the other hand, Rind et al. (2001b) explained the cooling in the GISS model as a consequence of an accelerated Antarctic Circumpolar Current, increased heat divergence and sea ice extent around Antarctica. Based on recent experiments using a coupled model of intermediate complexity, Knutti et al. (2004) showed a strong and extended bipolar seesaw response in the Southern Hemisphere. Their simulations used global salt compensation, and we must conclude that part of their warming and its synchroneity with the applied freshwater flux forcing in the North Atlantic were likely caused by this choice. Therefore, salt compensation tends to enhance the temperature response in the Southern Hemisphere by anomalies of the bolus velocity field, particularly when the perturbations are strong and applied as relatively short pulses.
Nevertheless, in the model intercomparison experiments by Stouffer et al. (2006), a clear warming in large parts of the Southern Hemisphere is obtained in the strong forcing case, although none of the model used salt compensation fluxes. The pattern of the warming is quite similar to that obtained with the present model for experiment cFN20 (see Fig. 2b). This suggests that the bipolar seesaw response is not an artifact of choices of freshwater forcing associated with global compensation, but can still be considered a characteristic global response of the climate system to large changes in the Atlantic MOC.

This is corroborated in experiments with a freshwater perturbation of a maximum of only $0.2 \mathrm{~Sv}$. In addition, we found that the compensation is unimportant. However, the GM mixing is crucial to spread the warming from the South Atlantic into the Southern Ocean through the mean bolus overturning that is caused by the outcropping isopycnals in the Southern Ocean.

Our results may also be important in the context of meltwater events around Antarctica during the Late Pleistocene. Marine sediments (Kanfoush et al. 2000) and global sea level reconstructions (Clark et al. 2002a) indicate that meltwater pulses have originated from Antarctica several times during the last ice age including the deglaciation phase. Indeed, model simulations suggest that changes in the surface buoyancy balance in the Southern Ocean can have far-reaching impacts on the global circulation and water mass composition. Freshening the densest waters of the World Ocean allows North Atlantic Deep Water to penetrate deeper and farther south in the Atlantic Ocean (Stocker et al. 1992a; Knorr and Lohmann 2003), and this may eventually trigger the resumption of a reduced $\mathrm{MOC}$ in the Atlantic. However, in another model, the global spreading of the freshwater from the Southern Ocean results in a nearly insensitive Atlantic MOC (Stouffer et al. 2007). Also, reducing the density of Antarctic Intermediate Water strengthens the Atlantic MOC and may constitute an important mechanism during deglaciation (Weaver et al. 2003).

Apparently, the combination of paleoclimatic reconstructions suggests a rather intricate coupling of the Northern and Southern Hemispheres during deglaciation (Stocker 2003). The mechanism we have proposed in this study would enhance the response of the sea surface to meltwater discharge around Antarctica. The meltwater first initiates a cooling because warmer waters are no longer being mixed up to the surface. The freshening moves the outcropping isopycnals poleward, which decreases their slope. Eddy-induced mixing decreases and produces a bolus heat divergence, which enhances the cooling. The enhanced cooling acts as to 
move the outcropping isopycnals equatorward and restore their position. In contrast to the North Atlantic, where $\Delta q$ dominates, the cooling caused by the divergence of bolus heat flux, $\Delta q^{*}$, could represent a major perturbation to the heat balance of the Southern Ocean.

Acknowledgments. We thank the model development team of NCAR and KNMI for providing state-ofthe-art climate models to the climate research community. This study was initiated during a sabbatical visit of TFS to IPRC, financial support and hospitality by IPRC are gratefully acknowledged. We are grateful to Uta Krebs who has discovered the effects of salt compensation on Southern Hemispheric climate in the ECBilt-CLIO model. Constructive comments by C. Raible, R. Stouffer, and two anonymous reviewers improved the presentation. Model simulations were performed at the University of Bern, at the Swiss Center for Scientific Computing in Manno, and at IPRC. This study is supported by the Swiss National Science Foundation, by NCCR Climate, and by the European Commission through Project EPICA-MIS. AT and OT are supported by the Japan Agency for Marine-Earth Science and Technology (JAMSTEC) through its sponsorship of the International Pacific Research Center.

\section{REFERENCES}

Broecker, W. S., 1998: Paleocean circulation during the last deglaciation: A bipolar seesaw? Paleoceanography, 13, 119-121.

Bryan, F. O., G. Danabasoglu, N. Nakashiki, Y. Yoshida, D.-H. Kim, J. Tsutsui, and S. C. Doney, 2006: Response of the North Atlantic thermohaline circulation and ventilation to increasing carbon dioxide in CCSM3. J. Climate, 19, 23822397.

Bryden, H. L., and S. Imawaki, 2001: Ocean heat transport. Ocean Circulation and Climate: Observing and Modelling the Global Ocean, G. Siedler et al., Eds., Academic Press, 455-474.

Clark, P. U., J. X. Mitrovica, G. A. Milne, and M. E. Tamisiea, 2002a: Sea-level fingerprinting as a direct test for the source of global meltwater pulse 1A. Science, 295, 2438-2441.

— , N. G. Pisias, T. F. Stocker, and A. J. Weaver, 2002b: The role of the thermohaline circulation in abrupt climate change. Nature, 415, 863-869.

Crowley, T. J., 1992: North Atlantic deep water cools the Southern Hemisphere. Paleoceanography, 7, 489-497.

Danabasoglu, G., J. C. McWilliams, and P. R. Gent, 1994: The role of mesoscale tracer transports in the global ocean circulation. Science, 264, 1123-1126.

EPICA Community Members, 2006: One-to-one coupling of glacial climate variability in Greenland and Antarctica. Nature, 444, 195-198.

Flückiger, J., R. Knutti, and J. W. C. White, 2006: Oceanic processes as potential triggers and amplifying mechanism for Heinrich events. Paleoceanography, 21, PA2014, doi:10.1029/ 2005PA001204.

Ganachaud, A., 2003: Large-scale mass transports, water mass formation, and diffusivities estimated from World Ocean Cir- culation Experiment (WOCE) hydrographic data. J. Geophys. Res., 108, 3213, doi:10.1029/2002JC001565.

Gent, P. R., and J. C. McWilliams, 1990: Isopycnal mixing in ocean circulation models. J. Phys. Oceanogr., 20, 150-155.

, J. Willebrand, T. J. McDougall, and J. C. McWilliams, 1995: Parameterizing eddy-induced transports in ocean circulation models. J. Phys. Oceanogr., 25, 463-474.

Goosse, H., and T. Fichefet, 1999: Importance of ice-ocean interactions for the global ocean circulation: A model study. $J$. Geophys. Res., 104, 23 337-23 355.

_ J. M. Campin, T. Fichefet, and E. Deleersnijder, 1997: Sensitivity of a global ice-ocean model to the Bering Strait throughflow. Climate Dyn., 13, 349-358.

Griffies, S. M., 2004: Fundamentals of Ocean Climate Models. Princeton University Press, $518 \mathrm{pp}$.

Hu, A., G. A. Meehl, and W. Han, 2007: Role of the Bering Strait in the thermohaline circulation and abrupt climate change. Geophys. Res. Lett., 34, L05704, doi:10.1029/2006GL028906.

Kanfoush, S. L., D. A. Hodell, C. D. Charles, T. P. Guilderson, P. G. Mortyn, and U. S. Ninnemann, 2000: Millennial-scale instability of the Antarctic ice sheet during the last glaciation. Science, 288, 1815-1818.

Keeling, R. F., and M. Visbeck, 2005: Northern ice discharges and Antarctic warming: Could ocean eddies provide the link? Quat. Sci. Rev., 24, 1809-1820.

Knorr, G., and G. Lohmann, 2003: Southern Ocean origin for resumption of Atlantic thermohaline circulation during deglaciation. Nature, 424, 532-536.

Knutti, R., J. Flückiger, T. F. Stocker, and A. Timmermann, 2004: Strong hemispheric coupling of glacial climate through freshwater discharge and ocean circulation. Nature, 430, 851-856.

Krebs, U., and A. Timmermann, 2007: Fast advective recovery of the Atlantic meridional overturning circulation after a Heinrich event. Paleoceanography, 22, PA1220, doi:10.1029/ 2005PA001259.

Lambeck, K., and J. Chappell, 2001: Sea level change through the last glacial cycle. Science, 292, 679-686.

Manabe, S., and R. J. Stouffer, 1994: Multiple-century response of a coupled ocean-atmosphere model to an increase of atmospheric carbon dioxide. J. Climate, 7, 5-23.

_ and _- 1997: Coupled ocean-atmosphere model response to freshwater input: Comparison to Younger Dryas event. Paleoceanography, 12, 321-336.

_ and - 1999: Are two modes of the thermohaline circulation stable? Tellus, 51A, 400-411.

_ and - 2000: Study of abrupt climate change by a coupled ocean-atmosphere model. Quat. Sci. Rev., 19, 285-299.

Mikolajewicz, U., and E. Maier-Reimer, 1994: Mixed boundary conditions in ocean general circulation models and their influence on the stability of the model's conveyor belt. J. Geophys. Res., 99, 22 633-22 644.

- M. Gröger, E. Maier-Reimer, G. Schurgers, M. Vizcaino, and A. M. E. Winguth, 2007: Long-term effects of anthropogenic $\mathrm{CO}_{2}$ emissions simulated with a complex earth system model. Climate Dyn., 28, 599-633.

Opsteegh, J. D., R. J. Haarsma, F. M. Selten, and A. Kattenberg, 1998: ECBILT: A dynamic alternative to mixed boundary conditions in ocean models. Tellus, 50A, 348-367.

Redi, M. H., 1982: Oceanic isopycnal mixing by coordinate rotation. J. Phys. Oceanogr., 12, 1154-1158.

Renssen, H., H. Goosse, and T. Fichefet, 2002: Modeling the effect of freshwater pulses on the early Holocene climate: The 
influence of high-frequency climate variability. Paleoceanography, 17, 1020, doi:10.1029/2001PA000649.

$\longrightarrow,-$, and $\longrightarrow, 2005$ : Contrasting trends in North Atlantic deep-water formation in the Labrador Sea and Nordic Seas during the Holocene. Geophys. Res. Lett., 32, L08711, doi:10.1029/2005GL022462.

Rind, D., P. Demenocal, G. L. Russell, S. Sheth, D. Collins, G. A. Schmidt, and J. Teller, 2001a: Effects of glacial meltwater in the GISS coupled atmosphere-ocean model: Part I: North Atlantic Deep Water response. J. Geophys. Res., 106, 27 33527354.

, G. L. Russell, G. A. Schmidt, S. Sheth, D. Collins, P. Demenocal, and J. Teller, 2001b: Effects of glacial meltwater in the GISS coupled atmosphere-ocean model: Part II: A bipolar seesaw in Atlantic Deep Water production. J. Geophys. Res., 106, 27 355-27 366.

Saenko, O. A., A. Schmittner, and A. J. Weaver, 2004: The Atlantic-Pacific seesaw. J. Climate, 17, 2033-2038.

Stocker, T. F., 1998: The seesaw effect. Science, 282, 61-62.

—, 2002: North-south connections. Science, 297, 1814-1815.

_ 2003: South dials north. Nature, 424, 496-499.

— deep circulation induced by changes in surface water fluxes. Nature, 351, 729-732.

— , and A. Schmittner, 1997: Influence of $\mathrm{CO}_{2}$ emission rates on the stability of the thermohaline circulation. Nature, 388, 862-865.

—_, and S. J. Johnsen, 2003: A minimum thermodynamic model for the bipolar seesaw. Paleoceanography, 18, 1087, doi:10.1029/2003PA000920.

— D. D. G. Wright, and W. S. Broecker, 1992a: The influence of high-latitude surface forcing on the global thermohaline circulation. Paleoceanography, 7, 529-541.

,-- , and L. A. Mysak, 1992b: A zonally averaged, coupled ocean-atmosphere model for paleoclimate studies. J. Climate, 5, 773-797.

Stouffer, R. J., and Coauthors, 2006: Investigating the causes of the response of the thermohaline circulation to past and future climate changes. J. Climate, 19, 1365-1387.
- D. Seidov, and B. J. Haupt, 2007: Climate response to external sources of freshwater: North Atlantic versus the Southern Ocean. J. Climate, 20, 436-448.

Talley, L. D., J. L. Reid, and P. E. Robbins, 2003: Data-based meridional overturning streamfunctions for the global ocean. J. Climate, 16, 3213-3226.

Tartinville, B., J. M. Campin, T. Fichefet, and H. Goosse, 2001: Realistic representation of the surface freshwater flux in an ice-ocean general circulation model. Ocean Modell., 3, 95108.

Timmermann, A., and H. Goosse, 2004: Is the wind stress forcing essential for the meridional overturning circulation? Geophys. Res. Lett., 31, L04303, doi:10.1029/2003GL018777.

— - S.-I. An, U. Krebs, and H. Goosse, 2005a: ENSO suppression due to weakening of the North Atlantic thermohaline circulation. J. Climate, 18, 3122-3139.

— , U. Krebs, F. Justino, H. Goosse, and T. Ivanochko, 2005b: Mechanisms for millennial-scale global synchronization during the last glacial period. Paleoceanography, 20, PA4008, doi:10.1029/2004PA001090.

— , and Coauthors, 2007: The influence of a weakening of the Atlantic meridional overturning circulation on ENSO. J. Climate, 20, 4899-4919.

Vellinga, M., and R. A. Wood, 2002: Global climatic impacts of a collapse of the Atlantic thermohaline circulation. Climatic Change, 54, 251-267.

Weaver, A. J., O. A. Saenko, P. U. Clark, and J. X. Mitrovica, 2003: Meltwater pulse 1A from Antarctica as a trigger of the Bølling-Allerød warm interval. Science, 299, 1709-1713.

Yeager, S. G., C. A. Shields, W. G. Large, and J. J. Hack, 2006: The low-resolution CCSM3. J. Climate, 19, 2545-2566.

Yokoyama, Y., T. M. Esat, and K. Lambeck, 2001: Coupled climate and sea-level changes deduced from Huon Peninsula coral terraces of the last ice age. Earth Planet. Sci. Lett., 193, 579-587.

Zhang, R., and T. L. Delworth, 2005: Simulated tropical response to a substantial weakening of the Atlantic thermohaline circulation. J. Climate, 18, 1853-1860. 